\title{
US COVID-19 EXAM FAILURE MAKES WORLD LEERY ABOUT AMER- ICAN EXCEPTIONALISM AND LEADERSHIP
}

\author{
Liviu Popa-Simil ${ }^{1} ه$ \\ ${ }^{1}$ LAAS - Los Alamos Academy of Sciences,, Mail: 199 Central Park Sq., Los Alamos, NM 87544-784, USA
}
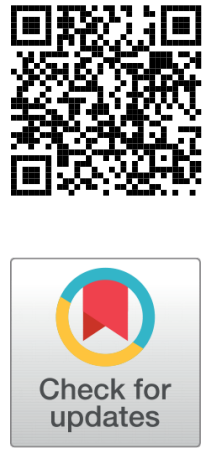

\section{ABSTRACT}

For a newbie in the USA, heath care, education, science and economy are presented as exceptional; the best of the world, but these nice words are not backed by reality, and it is hard to openly talk about these issues as they turn into an inconvenient truth, and the fact that truth is anti-American and anti-human makes it more difficult to correct the problems, as it turns difficult to openly acknowledge the issues and look for solutions. Trump and Covid revealed a bunch of American truths, removed the vail of kindness and exceptionalism, and put in the limelight a lot of inconvenient realities of the actual USA, a country ideologically divided and under Lord Covid, a nation sunk in alternate realities and facts, with a political leadership inept for progress. Looking to understand why this aberrant behavior in front of SARS-CoV-2 pandemic, we discovered that the $\mathrm{F}^{++}$grade USA obtained at this "ecologic" exam, is routed in education of the last 50 years, that produced such population with very low real IQ but

Received 24 June 2021

Accepted 9 July 2021

Published 20 July 2021

Corresponding Author

Liviu Popa-Simil, laaos@laaos.org

DOI 10.29121/

ijetmr.v8.i7.2021.987

Funding: This research received no specific grant from any funding agency in the public, commercial, or not-for-profit sectors.

Copyright: (C) 2021 The Author(s). This is an open access article distributed under the terms of the Creative Commons Attribution License, which permits unrestricted use, distribution, and reproduction in any medium, provided the original author and source are credited.

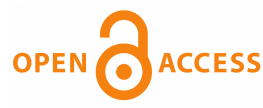
loud arrogant and oblivious of their situation, with little respect for reality and knowledge.

From the education stand point, the thinks appear even more complicated, because failures in education are routed in society, and the education system produced exactly what society asked and paid for, everything becoming a "chicken or egg" problem, under "what to solve first" dilemma

The present research was looking to find an answer to this very complex problem, at minimum to openly list the issues, and propose idealistic solutions, looking to become a wake-up moment not only for the USA but for many other nations which are confronted with the same issues, of a decadent democracy and consumerist economy, without pleading for extreme left solution manifested autocratic regimes.

Keywords: Iq, SarsCov2, Pisa, Education, Nature Exams

\section{INTRODUCTION}

It is no secret that with only $4 \%$ or World's population USA represents $25 \%$ of world's causalities being by a factor of 6 dumber than planetary averages, while comparing 
to countries as China, new Zeeland becomes scary Https://Www.Worldometers.Info/ Coronavirus / (n.d.). As everybody knows in detail how we reached that point it is less clear which are the determinant hidden factors that led to this tragic result. With 1.4 Billion population, India called a disaster when they reached the milestone of $\frac{1}{2}$ Million deaths, while in the USA with only $1 / 3$ of India's population $\frac{1}{2}+$ deaths is just business as usual, and large state openings are scheduled way in advance of illusory heard immunity being reached by mass vaccination. In fact very few countries understood the nature of this pandemic, the fact that there are no constitutional freedoms in front viruses Dellapelle (2020), and how to behave at national level in harmony with momentary protection needs and capabilities, and without any racist trend the fact that the Caucasian race was not among those smart nations Madden (2019) have to be acknowledged with all the sadness. In white people mind-set understanding nano-corpuscular behavior was impossibility; their brain was not "cabled" for that level of reasoning and understanding.

\section{REALISM OF IQ}

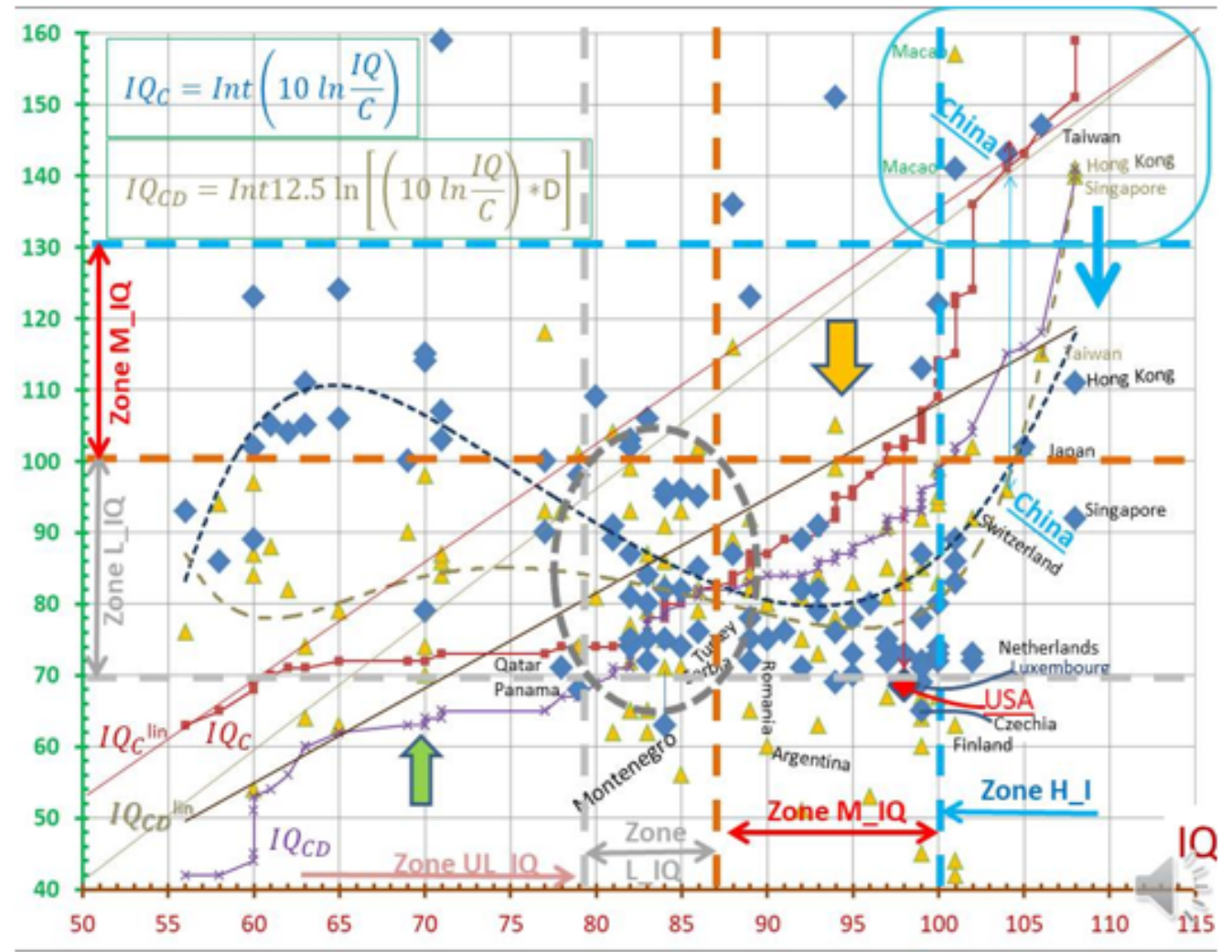

Figure 1 Corrected IQ toinfection rate and population density as function of primary IQ factor

Taking the national IQ factor Bohanon (2021) , from web: https://medium.com/ @loveaircoffee/highest-iq-in-the-world-2cea6698370e , USA is on place $27^{\text {th }}$, with 
an average IQ of 98 while China which in late Nov. Dec. 2019 was taken by surprise by covid-19 pandemic, and reacting in a military fashion as against a bio-terrorist attack, recording about $90 \mathrm{k}$ infections and over 4500 deaths has an IQ $=104.5$, led by Singapore and Hong Kong with 108, Taiwan and South Korea with 106, and Japan with 105. We plotted the infection rate in [\%], Https://Www.Worldometers.Info/Coronavirus/ (n.d.) , of various nations as a function of their IQ Madden (2019) , Bohanon (2021) and the result was surprising, showing that Covid and ecologic exams have been omitted from IQ evaluation, and a corrected IQ is needed. The new IQ is corrected by including the infection rate and population density in its formula, and is plotted as function of previous original IQ as shown in the Figure 1. One may observe that the countries really smart, with high IQ remain in top position, while the M_IQ (medium IQ) fall 1 category landing in the L_IQ (low IQ) zone, while L_IQ countries maintain their position with little changes inside the cloud. The UL_IQ countries are moving upwards towards M_IQ positions. USA in particular falls by 30 points from 98 to 68 inside UL_IQ zone. Formulae for the new IQ are given with their effect on cloud of countries. An in-depth analysis shows the primary IQ test was customized in order to keep Caucasian race happy, and happened that West Pacific shore Asian nations to outperform, while other races as Arab, African to be pushed down. The COVID test modified IQ is superficial, because the action is multi-scale- multi-dimensional and COVID by itself, do not cover the next "ecological exam", and the function has to be improved. As for now, taking a comparison between two largest world economies, USA and China that are at the very beginning of an escalating future confrontation, as US in spite lost the COVID exam, is uncomfortable losing the arrogant claim of leading role in world economy and accommodate into a multi-polar world order, dominated by China, we look more in-depth.

We know from WWI and WWII aftermath that countries with the best human capital recovered faster, and try an in-depth analysis inside human capital of the two rival countries, plotting Gaussians scaled with population factor Popa-Simil (2021) .

\section{COMPARING IQ AT FIRST 2 WORLD LEADING ECONOMIES}

In Figure 2 is given the distribution of IQs, knowing that the real distribution is not a single Gaussian, but a more complex function driven by many factors, as one may get if makes a histogram over initial IQ on 2.5 point large bins, showing about 4-5 components in the world's IQ composition, may be the 4 main races involved, with different cultural and religious backgrounds, but be aware there is not a simple explanation. Not having these fine distributions for our case the Gaussian reconstruction was a coarse approximation to obtain coarse results. One may easy observe that the total national IQ is proportional with surface under Gaussian, and based on this the No. Chinese with IQ>125 equals the entire USA population, and affirmative action has to be taken in order to correct this Popa-Simil (2021). 


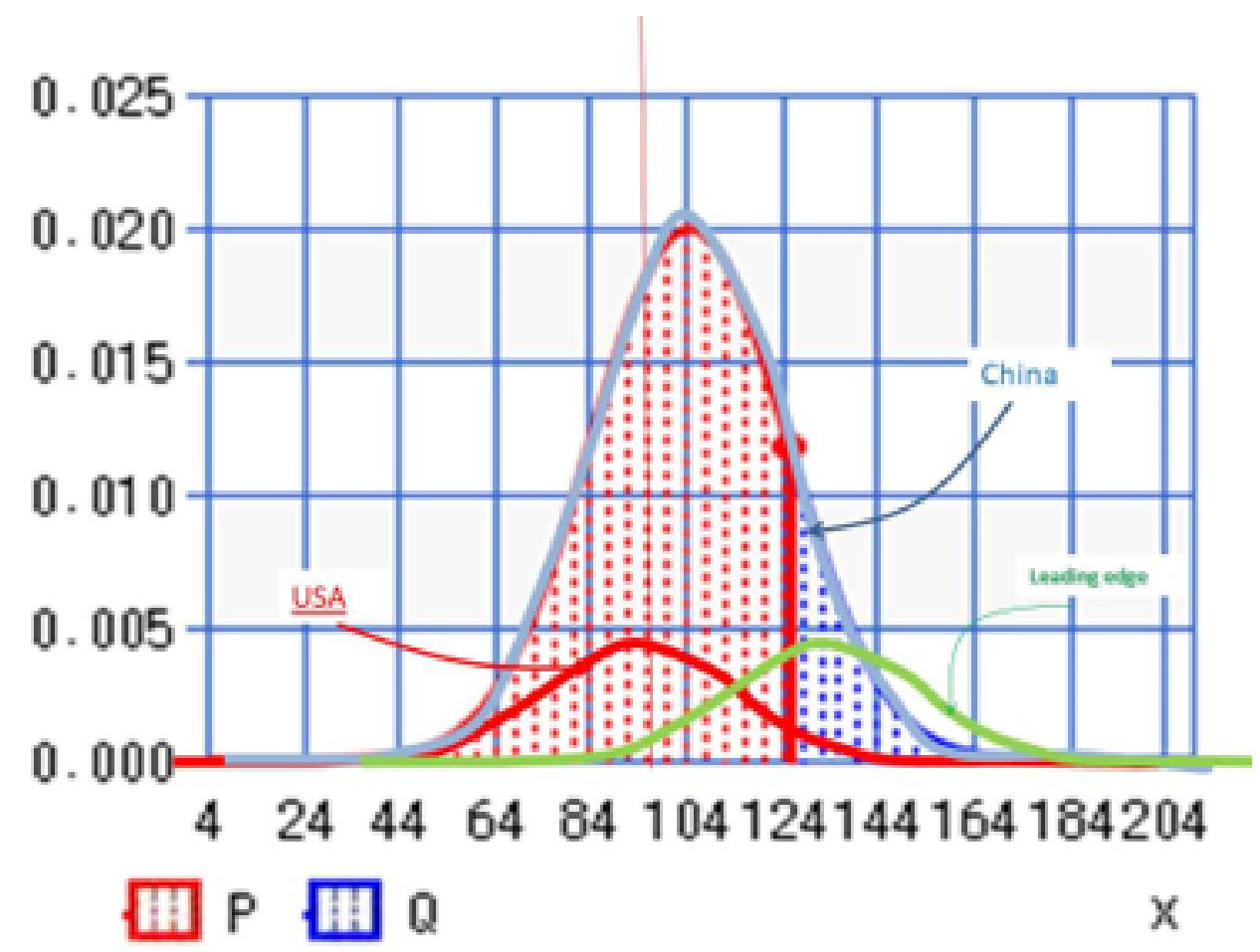

Figure 2 China vs USA IQdistributions

The US attempts to balance the difference of IQ power by military and phobia tools, is wrong, instead acting on education to move up the IQ curve at a mean IQ=135 and to assure a real, powerful leading edge at least of 1 Million Americans is an easier solution than in two decades growing the population at 2 Billion, or engaging in a nuclear war by 2030s under MAD (Mutually Assured Destruction). Biden administration I think consciently or not envisioned just that - intensive free education from pre-K to College, and broad-band internet infrastructure for the entire USA, hopefully to be used to better things than conspiracy theories and playing games and movies. If that's impossible we need to accept that we already lost the leading role in the world and adapt to a multi-polar world order, keep cooperating and recovering our national education in order to recreate a "leading edge". There is no clear path to recovery of $30 \%$ of the population living in alternate realities. Well it's easy to put blame on politicians - but are they the only ones involved? No; they have "basis" who elected them and sent them in that kabuki WDC. Then, at the root of this disaster may be the IQ level, but this is an effect of deeper causes rooted in the past and consumerist culture, the real American culture Garcia-Navarro (2021). Some may say that the disappearance and absence of a threat from an enemy as Soviet Union let USA in disarray accelerated the decadence of capitalism Nm_Pbs (n.d.), under new capitalism profit oriented surveillance, advertisement using internet media over the realms of reality and decency . 


\section{US GRIM REALITY OF EDUCATION}

Yes, we flew a drone on Mars, but making an "average Kentucky Joe" learn, that's painful and risky, and is a very complex endeavor, and that is why, US education is in big trouble and there is NO easy solution Popa-Simil and S (2019). Everything starts from the simple question: Why to learn more? What more education may bring to me in a society where the large majority of rich, successful people are drop-outs from school, or have iffy education in private colleges?

The social model promoted by Hollywood - propaganda organ of the USA - is not the scientist, the educated person, but a person "who can", and learn meanwhile or later if ever learns something. This are detrimental factors towards embedding a solid education, where student to develop the affective coupling, to understand that learning is painful if is done without pleasure, just memorizing the current lesson for show and a reward grade, than forget about it with the maximum pleasure. Therefore no matter what year in college or school a student is he is always in the first grade, being necessary to be explained everything from the very beginning as missing the fundamental bricks in the knowledge, everything being built on thin air. The old saying resulted from a talk between Einstein and Bohr, by 1925 where they stated: "Any foul can know the big problem is to understand", applies to US education that delivers knowledgeable fouls. This is easily shown by the PISA-OECD test Development (2020) , where USA has the most praised and expensive education system but performs behind world's average, where again, the Chinese, Asians, Scandinavians are in front, even Russians, and I do not wonder why., because Trump and COVID removed the vail covering the American realities, that are grim and require immediate corrective action. In fact, we do not lack corrective action ideas, what we massively miss, is a faithful acknowledgement of truth, that become "Anti-American", to anchor in reality the proposed corrective actions, in a democracy resembling two hands of the same body, holding each-other tight confronting and fighting each other and missing to grab the glass of water to drink.

\section{COMPARING EDUCATION PERFORMANCES OF OECD COUNTRIES}

An analysis at OECD-PISA test results in the last 20 years

https://en.wikipedia.org/wiki/Programme_for_International_Student_Assessm ent\#United_States show that things do not look good at all. It is not about money and education investments, but something more profound and complex.

The rank of the United States obtained in PISA test since 2000 for the subjects tested is nearby the average obtained for the 73 participant countries. It is seen that the US ranks below the average while Asian countries occupy the ranks one to five. Western Europe is above the average while the US is trailing the average with a decline tendency, except for science, that got a little growth by 2015 on the background of decline in Math and Reading. Not the same may be said about our nearby 
northern neighbor Canada, that occupies a position among the first 10, from rank 3 to 9 on all tests. Even Russia is above the average. Singapore, China, Japan are the champions! These countries have so smart kids and steal our patents???; Or this is just politics, and the truth is again against us - our enemy? That was true up to 1980s, but since then the things changed and we just do not want to see and acknowledge them.

\section{REASONS FOR STUDENTS' FAILURE}

shows for the US, Asians are performing the best, followed by white of different ethnicities, and those of Hispanic and black descent are the most disadvantaged. At a simple uneducated look, it seems that the attitude towards work of Asians dominates over that of whites in spite their higher welfare, while deep, inherited, poverty of black and Hispanics has real consequences on kids' results due to family background Development (2020).

Note: Be aware that the statistical distribution of students changed year by year, and is correlated with complex social factors such as $9 / 11$, economic crises, visa restrictions, jobs market, etc.

Making a brief analysis after GDP per capita and house hold income in 2016 one may see that is a correlation between the relative curves of performance in education and family welfare, and average performance in education is obtained for middle class families with $-5 \%$ under the average house hold income that means of about $\$ 50 \mathrm{k} /$ year and $70 \%$ over the average at about $\$ 80 \mathrm{k}-120 \mathrm{k} /$ year. Kids from rich families with few exceptions trend to perform worse than kids from middle class, because probably suffering from affluenza, does not give the necessary attention and importance to education knowing that using money and relations they will be just fine, without a great degree, inheriting the family business and they may hire educated people to work for them. We can ignore them because demographically they represent less than $10 \%$ of the students' population. At the other extreme, are the poor families representing more than $50 \%$ of the population, where because of poorness, kids are busy in after school hours, and in an homework intensive education system, conceived like this to hide average class teachers, they do not perform well and here is the real loss of the society.

Quality and preparedness level of the teachers is hard to evaluate Lu (1999), because the complexity of the problem, in spite is a fundamental issue, most of the criteria used today for such evaluation are bogus. It was thought that information provided that is unwanted, or unasked for, will not be appreciated, would be ignored or not understood; the real learning process occurs only if somebody is interested in finding the answer to a question or a problem that they consider to be important, and to which they pay attention. In order to have that, one needs to generate in the minds of students a state of affection, interest, and need for a certain subject, where the student will pay attention to the information and store it in his/her brain, and 
operate over it, to find its various aspects. Is that the case in US education? Most probable answer is NO.

This is a hot subject among educators, parents and politicians, everybody is asking for change, but no one knows what to be changed and how. A wide range of ideas and proposals are formulated or imposed without a real scientific base. The most frequent change is the managerial one, where the new manager changes everything his predecessor made, making the system bounce in disarray, based on empty rhetoric.

The actual model for the good students is this: learn by heart, give the show, and forget. That fact minimizes the usefulness of education and learning in the first years.

One reason for this is that the students do not have all the "knowledge foundation bricks" in place when a new "brick of knowledge" is added, and that has to float in thin air, because the CLASSES SYLLABI ARE NOT SYNCHRONIZED, and do not rely on each other.

For example, a subject taught in science is not related to subjects in mathematics or language, to be used as base and operational tools. See for example in $7^{\text {th }}$ or $8^{\text {th }}$ grade science: they learn about "genetic programming", but they had no idea what an amino acid is, nor nitrous acid, nor ammonia, and they started solving puzzles with letters...and of course 2 weeks after that was over they forgot everything, and that time and effort was simply lost.

Another correlation that is most often is between Math and Physics, where physics relies on math not yet taught to students. More physics is taught based on theoretical developments, instead of being correlated with the practical world, and the students are missing the most elementary notions from nature, that transforms physics in a bunch of blah, blah...nothing useful for life or with practical applications, therefore they graciously forget all the formulas they learned by heart, and they do not correlate the notions and work with them.

The problem here comes from the teachers, who 20 years ago they were taught this way, and from manuals made by university professors based on theory more than practice, making those scientists some parrots of science, and I will come with some examples:

Once, in a university I was working, a famous electrodynamics professor, who knew all Maxwell equations by heart, and was making excellent lessons on electrodynamics, came in my accelerator room near by a HV power supply, triggered my attention and I asked him to step back and he asked me offended: "What kills? Voltage or Current?", initially I took it as a joke, and laughed, but seeing him seriously concerned, I got worried and I tried not to offend him with a simple Ohm law explanation and biologic effect of the current, so I answered him: If you have doubts on that is better to stay away from both! And as he stepped back we changed the subject of discussion...everything went smooth, he left the room without being roasted, or carbon coated.

In my opinion, US education is missing the practical applicative education that creates the foundation bricks able to support the advanced theoretical knowledge. 
In computer literacy, the problem is even worse, because $99 \%$ of students do not understand computers, how they work, and become hostages of different programs and computer brands, performing complex operations outside of their control and knowledge, because nobody taught them the basics - such as Boolean algebra, numeration bases, logical gates, and fundamentals of programming. In a test applied to GATE kids in a Los Alamos school, some fundamental questions about computers were asked, and the kids provided $200 \%$ of the answers, proving that they heard almost anything about, the only problem was that they did not know which was right and which was wrong, and were to apply that answer correctly, proving that their knowledge was dangerously superficial.

\section{INITIATIVES TO IMPROVE EDUCATION}

There are many initiatives in education, (for example Mrs. Obama had about 7) which briefly are: The need for post-secondary education; The necessity of school counselors; Girls' education; Education for African-Americans; Arts education; Healthy school lunches; Fashion education, that is a mixture of everything and I'm not convinced that these are her original ideas, but some of them are meant to apply correction to the results observed in PISA tests.

For example, the healthy food school lunches come in contradiction with kids' appetite for junk food, which was induced for many years via all commercials, and as our current president showed recently, "fast food" is more appreciated than a natural healthy food. The sad truth behind the fact is that Hispanics, blacks (African Americans) and others coming from very poor families, are fighting for survival in the American dream, which for them is a nightmare.

We have to learn from the experience of communist countries which at school were providing food, after-hours education and bedroom, for poor kids for free and on payment for the rest of the kids, and which gradually turned them towards healthy food, not only junk fast food. I said junk fast food because not all fast food is junk, and not all-organic food is healthy...and schools have to move out from the realm of commercial advertisement, beyond lying, and develop their own menus, loved by kids and healthier

There are many others, such as "Inquiry education", "Play and learn", STEM literacy, etc., but while the US education is $80 \%$ based on homework, and most of the kids find something better to do after school, all these are prone to failure, in a society that misses incentives for higher education.

The first step is to understand what the top PISA countries are doing in order to improve our local system, and not to change it with a radically new system with flaws that we will only learn about after 20 years of failures.

In my mind, a spiral of progress consists of an education where one learns, repeats, redoes, improves oneself, is active, with a drastic reduction in homework, but based on fundamental knowledge mixed with practice, where the students will be able 
to understand and apply this knowledge in life, and where laboratory practice will match the theory and gradually upgrade, via repetition.

An important component is the psycho-affective component, where a student picks a subject or a domain he thinks he likes and fits his/her future aspirations and model of life.

An important role in this children selection is the models offered by society and how the society appreciates and rewards work, knowledge and honesty. Unfortunately US society does not appreciate hard work, honesty, science and math, and that is why the school makes desperate efforts to stimulate STEM. In the past $50 \%$ of college students in science departments were foreigners, mainly Asian kids, now these departments are under populated. Most of the American white (Caucasian) kids who graduate High School are looking for faculties that put them in a making money position after that as law, medicine, and business and very few are going into science.

The novel chino-phobia, ruso-phobia political inspired propaganda made less and less foreigners to apply for higher education in the US, while the autochthones are deterred by the arrogant manner US suffering of some affluenza, is treating its scientists, and do not find themselves bound in a such a future.

The thieving classes in US are lawyers, politicians, businesspeople, (honest or not, does not matter if they are rich), artists, sportsman, physicians where the most appreciated skills, are talking and human skills of hanging together in packs of connected people, and that are the raw models provided by our society, followed by the young generation.

The kids see and understand this and then, why to bother for science?

Social propaganda dominated by Hollywood and other movie houses, is doing more harm than good to education, promoting violence and sex, apparently these being something most of American market understands and likes to see, people paying for. The main characters are appreciated for other virtues than education, and where the US is always the good guys no matter what damage and pain they inflict to others, giving masses a false image of reality.

\section{SYNTHESIS OF ADVICES TO GRADUALLY CORRECT THE EDUCATION AS TO END-UP WITH A CORRECTED SOCIETY}

This is a list of measures aiming at correcting the education first applied to younger generation first simultaneously with measures applied for adult society:

1. Extend the education from day-care for toddlers to college, where to be in a kindergarten regime, that to foster respect for science and knowledge, as recently Biden administration proposed.

2. Synchronize the knowledge gradual approach, by synchronizing reading and cognitive capabilities with the ability to learn and digest science, starting from basis and experiments and gradually reaching advanced theory supported by 
math. Learning practical basic skills to do with their hands will be most recommended.

3. Start training and retraining of the teachers, and create incentives for them to accept the knowledge.

4. Leave grades and results in public domain, and stir the competition for best places inside class and among classes, creating an after-hours education for those with bad results, as to provide them with supplementary explanations, as to understand and advance gradually in complexity.

5. Make homogeneous classes selecting after education level, as to be possible to help advanced students learn more, while the weak students learn what is right for their level as to understand and master it, following variable paths for ending high school, from 12 years to 15-16 years, but remain assured that after that period they master equally well the HS subjects and are ready for college.

6. Instauration of boarding schools for poor and weak students where to spend almost the entire week in a controlled environment that to expose them to learning alternated with sport activities and recreational activities, under careful supervision.

7. Develop affective state versus learning and performance; stimulate their creative thinking and innovation, involving them in afterhours creative activities and sports.

8. Society has to debunk the alternate realities and misinformation promoted via internet, media outlets political channels, introducing responsibility and penalties for lies and misinformation. Stress for character, and right morale of society, truths and right set of values.

\section{CONCLUSIONS}

In conclusion we need to take this $\mathrm{F}^{++}$we got at SARS-CoV-2 planetary exam as a wake-up signal, allow the truth to be acknowledged, in order to tailor the best corrective actions, and introduce some decency in our usual bragging on anything, but avoid falling in the opposite extreme of deception and depression, that may incapacitate our thinking and reasonable action. Only by solving the education problem, we may restore our planetary leading role, as a smart power, as we really represent $4 \%$ or world's population, "by the power of our example".

Without ample corrective actions, USA future is grim, and from a democracy it may fail into a totalitarian regime, that desperately is trying to maintain some of the previous positions from the past, even inflicting world wars, that attracts a Mutual Assured Destruction. USA have to move forward from a "Darth Vader Empire" into a smart power, followed by other nation by its "power of its example", accept a multi polar world, and prepare itself as to advance its population and technology in a real leadership position, by changing itself in order to change the planet. 
Meanwhile China and India the most populous countries will take economic and scientific leadership, as soon as they succeed to rise their intellectual and manufacturing power, and only by an exceptional education for real, USA may maintain the leadership.

There is no single solution for education advancement, but one has to consider the deep interconnection between education and social and moral values of a society, their aspirations and concept of good, welfare and integration with the planetary conditions and environment.

\section{REFERENCES}

Bohanon, C. (2021). “Economic Recovery: Lessons From The Post-World War Ii Period”, Mercatus Center At George Mason University,

Dellapelle, A. F. (2020). Constitutional Implications Of Covid-19 And Its Impact On Property Rights And Personal Liberties" July 27,. Retrieved from Https://Www.Americanbar $.0 \mathrm{rg} /$ Groups/Litigation/Committees

Development, T. C. F. W. E. (2020). "Attitude Really Is Everything And Here's Why".

Garcia-Navarro, L. (2021). "The Myth Of American Exceptionalism", January 10, . Npr, National.

Lu, X. (1999). Teacher Quality And Teacher Quality And Teacher Preacher Preparedness In Public Second Redness In Public Secondary", Schools: Evidence From Sass. Dissertations Graduate College, 12.

Madden, D. (2019). Ranked: The 25 Smartest Countries In The World, Forbes, Jan 11,. Forbes. Retrieved from Https://Worldpopulationreview.Com/Country-Rankings/Average-Iq -By-Country

Nm_Pbs. (n.d.). The Rise Of American Consumerism. Retrieved from Https://Www.Pbs.Org/ Wgbh/Americanexperience/Features/Tupperware-Consumer/

Oecd, . ., \& Pisa. (2021). "Pisa 2021 Integrated Design”. Retrieved from Https://Www.Oecd .0rg/Pisa/Pisaproducts/Pisa2021_Integrateddesign.Pdf

Popa-Simil, L. (2021). Inconvenient Truth On Covid-19 Disaster In The Usa And How It Might Have Been Avoided, April,. Retrieved from Https://Www.Youtube.Com/ Channel/Ucnlzzdnikwtdyh4z-9xzalg

Popa-Simil, L., \& S, . U. (2019). “U.S. Education Is In Deep Trouble And There Is No Easy Solution”. Los Alamos Reporter.

(n.d.). Retrieved from Https://Www.Worldometers.Info/Coronavirus/ 